\title{
RADIOCARBON DATING OF ANCIENT CANOES FROM GUANGXI, CHINA
}

\author{
Yongjing Guan ${ }^{1}$ Xiangdong Ruan ${ }^{1,2} \bullet$ Zhaoming Xiong $^{3} \cdot$ Huijuan Wang ${ }^{1}$ Filippo Terrasi $^{4}$ \\ ABSTRACT. Several canoes were excavated from coastal rivers in the Guangxi Zhuang Autonomous Region, southwest \\ China. In order to confirm the age of the canoes, 6 samples were selected for radiocarbon dating from 3 canoes. The mean \\ value of canoe NLJ was $365 \pm 35 \mathrm{BP}$, and 2 samples from canoes MLJ and DFJ were $520 \pm 21$ and $499 \pm 33 \mathrm{BP}$, respectively. \\ The calendar ages cover a period from $\mathrm{AD} 1328$ to 1641 at the $95 \%$ confidence level. These results disagree with previous \\ studies that suggested canoes were only used over $1000 \mathrm{yr}$ ago in China. We discuss the possible reasons for the results being \\ younger than expected.
}

\section{INTRODUCTION}

The Guangxi Zhuang Autonomous Region is located in southwest China. The total land area of Guangxi is $236,700 \mathrm{~km}^{2}$, accounting for just $2.5 \%$ of the national total but is one of the most abundant water regions in China. The total number of rivers with a catchment area larger than $50 \mathrm{~km}^{2}$ in Guangxi is more than 1000. The rivers belong to different basins, including the Pearl River basin, the Yangtze River basin, the coastal rivers of south Guangxi and Red River basin, according to their source region and geographical position. The coastal rivers of south Guangxi comprise a total catchment area of $24,386 \mathrm{~km}^{2}$, i.e. $10.3 \%$ of total area of Guangxi Province, and include the main coastal rivers of Nanliu, Dafeng, Qiangjiang, Fangcheng, Maolian, and Beilun.

In regions like Guangxi where the topography is mountainous and water transportation is feasible, boats are the most efficient means of moving goods and people. Thus, canoes play an important role in the history of this region. Based on the appearance of different styles, canoe types can be divided into 3 periods: germination period; development and prosperity period; and the decline and fall period. It is thought that the canoe appeared in China in the Neolithic, approximately $8000 \mathrm{yr}$ ago, and slowly disappeared from the Han Dynasty (206 BC-AD 220) to Song Dynasty (AD 960-1279) due to the advance of shipbuilding technology and requirement for increasing load capacity.

In 2001, the earliest known canoe from China was excavated in Xiaoshan City, Zhejiang Province, which was dated between 6991 and 7070 BP (Jiang and Liu 2005). About 40 ancient canoes have been uncovered in different sites over the past $50 \mathrm{yr}$ in China, and most of these canoes dated to between 5000 and $1000 \mathrm{yr}$ old. For example, in 1960, 4 canoes belonging to the same period with an age of $1215 \pm 70$ BP were found at the Xishan site, Wenzhou City, Zhejiang Provience (Jin 1990), and in 1965 a canoe dated to $2900 \pm 75$ BP was found at the Yancheng site, Jiangsu Province (Zhou et al. 1999). In 2004, 2 canoes were found to be $1200-1300 \mathrm{yr}$ old based on the association with datable artifacts from Shandong Province (Cui 2004), and in 2009, a canoe with an age $3185 \pm 40$ BP was excavated in Xinyang, Henan Provience (Hu 2010). Further details on other excavations of canoes can be found in $\mathrm{Wu}(2008)$ and Yuan (1994). The existence and use of canoes was obviously influenced by the emerging shipbuilding technology, which is evident in the age distribution of the excavated canoes. The development of ships and shipbuilding technology in ancient China is described by $\mathrm{Qu}$ and Chen (2008).

\footnotetext{
${ }^{1}$ Department of Physics and GXU-NAOC Center for Astrophysics and Space Sciences, Guangxi University, Nanning 530004, China.

${ }^{2}$ Corresponding author. Email: yjguan@gxu.edu.cn.

${ }^{3}$ Guangxi Provincial Institute of Cultural Relics and Archaeology, Nanning 530023, China.

${ }^{4}$ Department of Environmental Sciences, Second University of Naples, Via Vivaldi 43, 81100 Caserta, Italy.
}

(C) 2013 by the Arizona Board of Regents on behalf of the University of Arizona Proceedings of the 21st International Radiocarbon Conference edited by A J T Jull \& C Hatté RADIOCARBON, Vol 55, Nr 2-3, 2013, p 1366-1370 


\section{Y Guan et al.}

In this study, we collected 6 wood samples from 3 canoes for radiocarbon dating, from Nanliu River, Maolin River, and Dafeng River, respectively. Since all 3 canoes were discovered during dredging projects, no associative artifacts such as coins or pottery can be used to correlate their age.

\section{SAMPLING SITES AND METHODS}

The arrows shown in Figure 1 indicate the specific position from which the canoes were excavated from the 3 different rivers. The Nanliu River site is located in the lower reaches of Nanliu River in Beihai, Guangxi Province. Canoe NLJ was removed from an underwater sand bed over $10 \mathrm{~m}$ deep during sand mining in the summer of 2002; the canoe was broken into 2 parts. About two thirds of the canoe, $6.2 \mathrm{~m}$ in length and $1.05 \mathrm{~m}$ in width, was removed, and the other part remained in the sand bed.

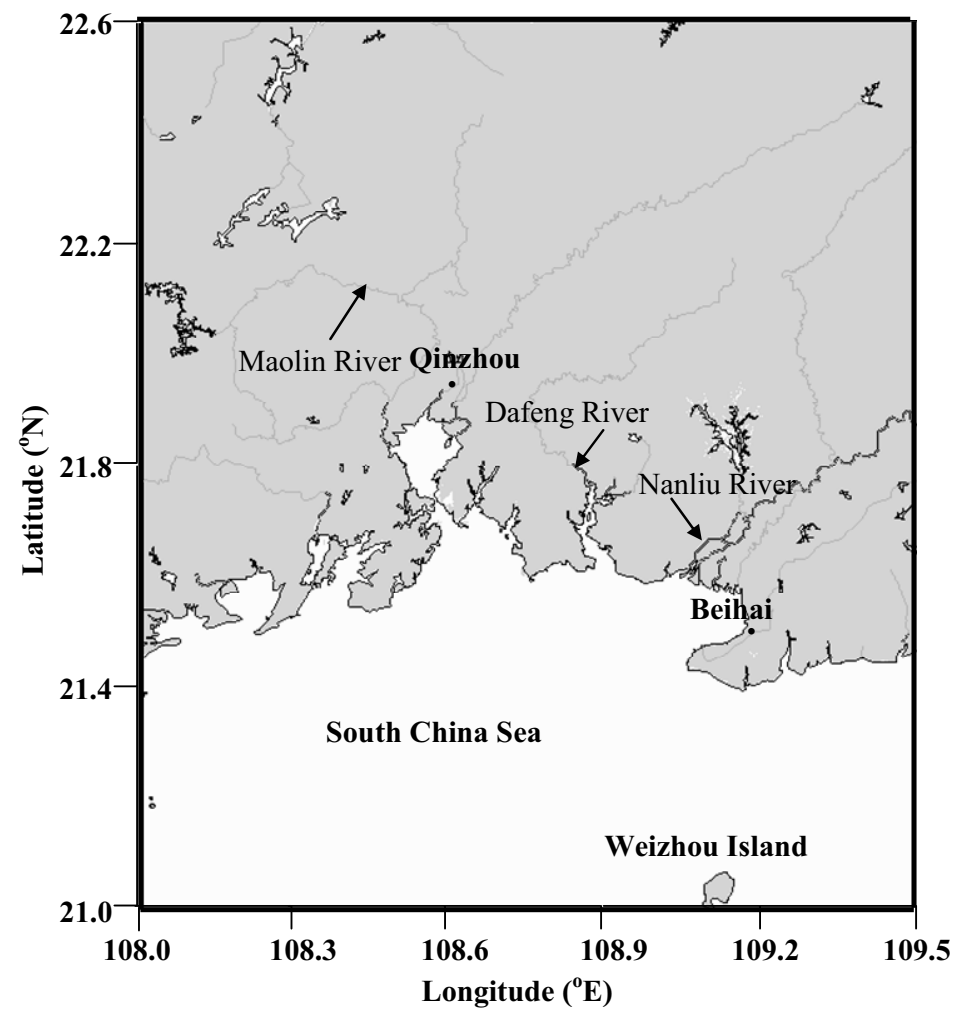

Figure 1 Location of sampling sites in the coastal region of south Guangxi. Arrows indicate the excavation sites of the canoes.

The other 2 well-preserved canoes MLJ and DFJ were discovered in the Maolin River and Dafeng River, respectively, during waterway regulation works for the city of Qinzhou (Figure 1). In fact, there have been 8 canoes discovered in the region of Qinzhou in the past $30 \mathrm{yr}$, but only 6 canoes were kept (Wu 2008). The shape, manufacturing technology, and wood species for all 6 canoes are similar. Thus, 2 of these, MLJ and DFJ, were selected for dating. According to the identification of wood species, the canoes were all made of camphor wood (Cinnamomum sp.). The Maolin River site is located in the northwest of Qinzhou, $\sim 30 \mathrm{~km}$ away from the river mouth (Figure 1). Canoe MLJ is $9.2 \mathrm{~m}$ in length and has a maximum width of $0.95 \mathrm{~m}$. The Dafeng River site is located in the 
southeast of Qinzhou, $\sim 20 \mathrm{~km}$ away from the river mouth (Figure 1). Canoe DFJ is $7.8 \mathrm{~m}$ in length, and is slightly narrower than canoe MLJ. The interior and exterior surfaces of all the canoes are smooth and flat. Their manufacturing technology was better than other early excavated canoes from nearby sites. Some regular chisel spots, not burnt spots, are visible on the interior surface, indicating that the ages of the canoes are not very old.

Four wood samples from different parts of canoe NLJ (namely, the prow, stern, larboard, and starboard) were processed with acid-alkali-acid (AAA) treatments and combusted to $\mathrm{CO}_{2}$. The purified $\mathrm{CO}_{2}$ was reduced to graphite with $\mathrm{H}_{2}$ over $\mathrm{Fe}$. These 4 samples were prepared and measured in the School of Archaeology and Museology of Peking University using the compact AMS system at the Peking University (PKU-AMS; Liu et al. 2007). Another 2 individual wood samples that were drilled from the prow of canoes MLJ and DFJ were also pretreated by the AAA method. The wood sample material was converted into a graphite target using the modified zinc reduction method (Marzaioli et al. 2008) at the CIRCE laboratory, Naples Second University, and measured with the CIRCE 3MV AMS system (Terrasi et al. 2008). Sample details and measurement results are given in Table 1.

Table 1 Results of ${ }^{14} \mathrm{C}$ and calibrated ages of canoes from Guangxi, China.

\begin{tabular}{|c|c|c|c|c|c|}
\hline \multirow[b]{2}{*}{ Sample } & \multirow{2}{*}{$\begin{array}{l}\text { Sample } \\
\text { description }\end{array}$} & \multirow[b]{2}{*}{ Lab code } & \multirow{2}{*}{$\begin{array}{l}{ }^{14} \mathrm{C} \text { age } \\
\mathrm{BP}\end{array}$} & \multicolumn{2}{|c|}{ Calendar age } \\
\hline & & & & $1 \sigma(68.2 \%)$ & $2 \sigma(95.4 \%)$ \\
\hline \multirow[t]{4}{*}{ NLJ } & Wood, starboard & BA051039 & $360 \pm 35$ & $\begin{array}{l}\text { AD } 1466(0.54) 1522 \\
\text { AD } 1574(0.46) 1627\end{array}$ & $\begin{array}{l}\text { AD } 1450(0.49) 1530 \\
\text { AD } 1538(0.51) 1635\end{array}$ \\
\hline & Wood, larboard & BA051040 & $390 \pm 35$ & $\begin{array}{l}\text { AD } 1446(0.82) 1514 \\
\text { AD } 1601(0.18) 1617\end{array}$ & $\begin{array}{l}\text { AD } 1440(0.68) 1525 \\
\text { AD } 1557(0.32) 1632\end{array}$ \\
\hline & Wood, stern & BA051041 & $370 \pm 35$ & $\begin{array}{lll}\text { AD } 1453(0.71) & 1521 \\
\text { AD } 1591(0.29) & 1620\end{array}$ & $\begin{array}{l}\text { AD } 1446(0.55) 1530 \\
\text { AD } 1540(0.45) 1635\end{array}$ \\
\hline & Wood, prow & BA051042 & $340 \pm 35$ & $\begin{array}{l}\text { AD } 1488(0.34) 1527 \\
\text { AD } 1555(0.66) 1632\end{array}$ & AD 1467 (1) 1641 \\
\hline DFJ & Wood, prow & DSH1342 & $499 \pm 33$ & AD 1412 (1) 1440 & $\begin{array}{l}\text { AD } 1328(0.03) 1341 \\
\text { AD } 1395(0.97) 1450\end{array}$ \\
\hline MLJ & Wood, prow & DSH1433 & $520 \pm 21$ & AD 1409 (1) 1429 & $\begin{array}{l}\text { AD } 1330(0.02) 1339 \\
\text { AD } 1397(0.98) 1440\end{array}$ \\
\hline
\end{tabular}

\section{Calibration}

The ${ }^{14} \mathrm{C}$ ages of the canoes are given in Table 1 together with their calibrated calendar age ranges. The mean value of canoe NLJ from Nanliu River site was $365 \pm 35 \mathrm{BP}$, and the 2 samples from canoes MLJ and DFJ were $520 \pm 21$ and $499 \pm 33$ BP, respectively. For each sample, the calibrated age is considered at the $68.2 \%$ and $95.4 \%$ confidence intervals using the OxCal online software v 4.1 (Bronk Ramsey 2009) and the IntCal09 calibration curve (Reimer et al. 2009). The results indicate that 3 canoes were all built in the Ming Dynasty (AD 1368-1644). Figure 2 summarizes the ${ }^{14} \mathrm{C}$ ages and calibrated ages of the 3 canoes from the different coastal rivers of south Guangxi.

\section{CONCLUSIONS AND DISCUSSIONS}

Our study of 3 different canoes using 6 different samples shows that the calendar ages of all the samples cover a period from AD 1328 to 1641 at the $95 \%$ confidence level. The results obtained give ages of cal AD 1440-1641 for canoe NLJ, cal AD 1328-1450 for canoe DFJ, and cal AD 13301440 for canoe MLJ. Thus, it is clear that the use of canoes lasted much longer than previously 


\section{$Y$ Guan et al.}

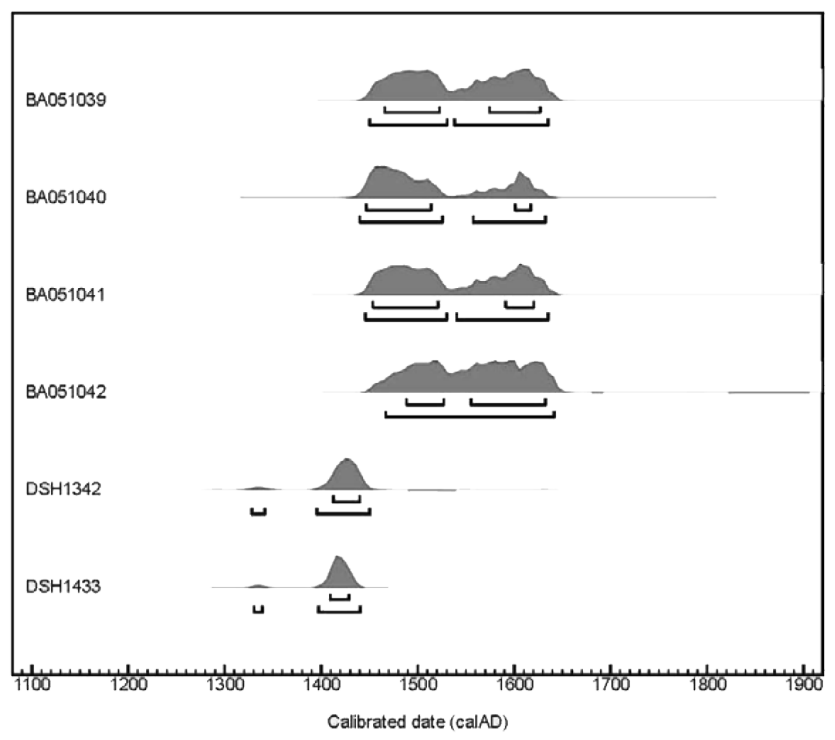

Figure 2 Combined probability distribution of wood ages from all 6 samples. The software used is OxCal online software v 4.1.

believed. Canoes played an important role in ancient China during a long period, but slowly disappeared in most areas in the Han and the Tang dynasties (206 BC-AD 220 and AD 618-907) due to the advance of shipbuilding technology. All of the canoes excavated from other sites present in the literature with are older than $1200 \mathrm{yr}(\mathrm{Wu} 2008$; Qu et al. 2008). However, all 3 canoes excavated from Guangxi were built in the last 500-700 yr, and the ages are at least $500 \mathrm{yr}$ younger. We conclude that canoes continued to be used until more recently in the coastal region of south Guangxi than in other regions. These more recent results can be explained by the 1) abundant water resources in the region and 2) the relatively low cost of a canoe. As previously discussed, Guangxi contains several rivers and some mountains that are difficult to traverse. Thus, in this region, a boat is the most efficient means of moving goods and people. Up to now, according to the literature (Qu et al. 2008) and our results, relatively young canoes from all the excavated and dated canoes are mainly distributed in the coastal rivers of Guangdong, Guangxi, and Fujian provinces. There are suitable trees growing in the region for preparing the canoe. Although shipbuilding technology sufficiently advanced to build larger wooden boats, it was relatively easy and cheap to fabricate a simple canoe. A simple canoe was enough for the regular daily use in the past centuries.

\section{ACKNOWLEDGMENTS}

This work was supported by grants from the National Science Foundation of China (41166002 and 11025313), and partly supported by the Guangxi Natural Science Foundation (Contract Nos. 2011GXNSFC018016, 2012GXNSFFA060005, and 2013GXNSFFA019001) and the Special Foundation for Distinguished Expert Program of Guangxi. We would like to thank Prof Kexin Liu (Peking University) for AMS measurement of canoe NLJ. We would also like to thank Manuela Capano and Isabella Passariello (CIRCE, Italy) for sample preparation of canoes DFJ and MLJ. 


\section{${ }^{14} \mathrm{C}$ Dating of Ancient Canoes from Guangxi, China}

\section{REFERENCES}

Bronk Ramsey C. 2009. Bayesian analysis of radiocarbon dates. Radiocarbon 51(1):337-60.

Cui T. 2004. Canoe belongs to Sui and Tang Dynasties was excavated in Laizhou, Shandong. China Cultural Relics News, 2004-11-12(2). In Chinese.

$\mathrm{Hu}$ J. Canoe belongs to Shang Dynasty was excavated in Xinyang. Henan Daily, 2010-8-7(3). In Chinese.

Jiang L, Liu L. 2005. The discovery of an 8000-year-old dugout canoe at Kuahuqiao in the Lower Yangzi River, China. Project Gallery 305. Antiquity 79: URL http://www.antiquity.ac.uk/projgall/liu/.

Jin B. 1990. Canoe belongs to Tang dynasty excavated in Xishan site, Wenzhou City. Archaeology 12:1138-9. In Chinese.

Liu K, Ding X, Fu D, Pan Y, Wu X, Guo Z, Zhou L. 2007. A new compact AMS system at Peking University. Nuclear Instruments and Methods in Physics Research B 259(1):23-6.

Marzaioli F, Borriello G, Passariello I, Lubritto C, De Cesare N, D'Onofrio A, Terrasi F. 2008. Zinc reduction as an alterative method for AMS radiocarbon dating: process optimization at CIRCE. Radiocarbon 50(1): $139-49$.

Qu J, Chen Z. 2008. An Introduction to Chinese Art Heritage of Marine Culture: Pre-Qin Dynasty and QinHan Dynasties. Qingdao: China Ocean University
Press. p 292-326. In Chinese.

Reimer PJ, Baillie MGL, Bard E, Bayliss A, Beck JW, Blackwell PG, Bronk Ramsey C, Buck CE, Burr GS, Edwards RL, Friedrich M, Grootes PM, Guilderson TP, Hajdas I, Heaton T, Hogg AG, Hughen KA, Kaiser KF, Kromer B, McCormac FG, Manning SW, Reimer RW, Richards DA, Southon JR, Talamo S, Turney CSM, van der Plicht J, Weyhenmeyer CE. 2009. IntCa109 and Marine09 radiocarbon age calibration curves, $0-50,000$ years cal BP. Radiocarbon 51(4): 1111-50.

Terrasi F, De Cesare N, D'Onofrio A, Lubritto C, Marzaioli F, Passariello I, Rogalla D, Sabbarese C, Borriello G, Casa G, Palmieri A. 2008. High precision ${ }^{14} \mathrm{C}$ AMS at CIRCE. Nuclear Instruments and Methods in Physics Research B 266(10):2221-4.

Wu C. 2008. Prehistoric transportation means in Southeast of China and Pacific Ocean. Relics from the South 2:99-108. In Chinese.

Yuan X. 2004. Comparative study between Xia'an shipwreck and other ancient boats in wreck in China. Contemporary Korea 4:25-9. In Chinese.

Zhou J, Zhao Y, Zhuang H. 1999. Reconstruction of the canoe unearthed in Yancheng site. Eastern and Southern Culture 3:122-3. In Chinese. 